\title{
Studi Komparatif Ukuran Pipa Endotrakeal tanpa Cuff pada Pasien Pediatri berdasar atas Diameter Subglotis dengan Metode Konvensional
}

\author{
Khildan Miftahul Firdaus, Elizeus Hanindito, Bambang Pujo Semedi \\ Departemen Anestesi dan Terapi Intensif \\ Fakultas Kedokteran Universitas Airlangga RSUD Dr Soetomo Surabaya
}

\begin{abstract}
Abstrak
Anatomi jalan napas pediatri menyebabkan pemilihan ukuran pipa endotrakeal (ETT) menjadi tantangan tersendiri. Pipa endotrakeal (ETT) yang terlalu kecil/besar meningkatkan risiko komplikasi. Prediksi ukuran ETT berdasar atas usia merupakan metode yang paling sering digunakan namun ternyata tidak selalu tepat pada aplikasinya. Parameter lain seperti diameter subglotis atau diameter kelingking tangan dapat menjadi alternatif untuk memprediksi ukuran ETT pediatri. Tujuan penelitian ini menganalisis dan membandingkan akurasi prediksi ukuran ETT tanpa cuff berdasar berbagai variabel pada pasien pediatri di RSUD Dr Soetomo Surabaya mulai Februari hingga April 2020. Subjek penelitian ini pasien usia 2-9 tahun, PS ASA 1-2 yang akan dilakukan operasi elektif. Saat preoperatif, usia, berat, dan panjang badan dicatat. Saat intraoperatif, diameter kelingking tangan dan diameter subglotis menggunakan USG diukur dan dicatat. ETT yang digunakan adalah ETT tanpa cuff berdasar atas diameter subglotis. ETT dianggap tepat apabila memberikan audible air leak pada tekanan 10-25 cmH20. Bila ETT terlalu kecil/besar maka dilakukan reintubasi. Tiaptiap parameter dilakukan uji korelasi, agreement test, serta predictive performance menggunakan MAPE, dan RMSE. Dari 48 pasien, didapatkan hasil bahwa prediksi ukuran ETT tanpa cuff berdasar atas diameter subglotis memiliki akurasi yang paling baik hingga 91,67\% ( $r=0,973$, koefisien kappa 0,892; $<<0,001$, MAPE $0,803 \%$, dan RMSE 0,144). Simpulan, prediksi berdasar atas diameter subglotis merupakan metode yang akurat untuk memprediksi ukuran ETT tanpa cuff pediatri.
\end{abstract}

Kata kunci: Berat badan aktual, berat badan ideal, diameter subglotis, pipa endotrakeal tanpa cuff, prediksi pipa endotrakeal pediatri

\section{Subglottic Diameter Ultrasonographic Assessment for Estimating Pediatric Uncuffed Endotracheal Tubes Compared to Conventional Methods}

\begin{abstract}
Anatomical differences in pediatric airways could be quite a challenge. Choosing endotracheal tube (ETT) optimum size is essential as a larger or smaller tube may cause undesirable complications. ETT size prediction based on age formula is most commonly used, but is not always successful. The little finger diameter and subglottic diameter are alternative parameters to predict pediatric uncuffed ETT optimum size. This study analyzed and compared the multiple variable-based formulas' accuracy to predict the pediatric uncuffed ETT optimum size. The ETT prediction used subglottic diameter-based formulas. Clinically fit ETT has an audible air leak within the pressure of $10-25 \mathrm{cmH} 20$. If the ETT predicted was relatively too small/ big than clinically fit ETT, it was changed to one size smaller/bigger. Each variable was then analyzed by correlation test, regressed against clinically fit ETT to test the agreement rates, and predictive performance was assessed using mean absolute percentage error (MAPE), and root mean square error (RMSE). From 48 patients it found that subglottic diameter formulas offered the best result in predicting optimum size uncuffed ETT in pediatrics with an agreement rate up to 44 of 48 patients got the right clinically fit uncuffed ETT (91.67\%, r=0.973, kappa 0.892, p-value $<0.001$, MAPE 0.803\%, and RMSE 0.144). In conclusion, the prediction based on subglottic diameter using USG is the best method to predict the optimum size of uncuffed ETT in pediatrics.
\end{abstract}

Keywords: Actual body weight, ETT prediction in pediatric, ideal body weight, subglottic diameter, uncuffed ETT

Korespondensi: Khildan Miftahul Firdaus, dr., Departemen Anestesi dan Terapi Intensif Fakultas Kedokteran Universitas Airlangga RSUD Dr. Soetomo Surabaya, Jl. Mayjen Prof. Dr. Moestopo No.6-8, Airlangga, Kec. Gubeng, Kota SBY, Jawa Timur 60286, Tlpn (031) 5501078, Email khildanmf@gmail.com 


\section{Pendahuluan}

Kegawatdaruratan pasien pediatri merupakan kasus yang sering kita temukan dalam keseharian seorang ahli anestesi. Hal ini menyebabkan manajemen jalan pernapasan merupakan satu kemampuan dasar yang harus dimiliki oleh seorang ahli anestesi. ${ }^{1}$

Pasien pediatri memiliki karakteristik dan anatomi jalan napas yang berbeda dibanding dengan pasien dewasa. Seiring dengan berjalannya pertumbuhan, pasien pediatri akan mengalami pertumbuhan pada jalan napas atau trakea. Hal ini menyebabkan variasi ukuran pipa endotrakeal pada pasien pediatri. Pemilihan ukuran pipa endotrakeal yang tepat merupakan syarat mutlak dalam manajemen jalan napas pada pasien pediatri. Ukuran pipa endotrakeal yang terlalu kecil dapat menyebabkan ventilasi tidak adekuat, pengukuran end-tidal $\mathrm{CO}_{2}$ tidak dapat diandalkan, kontaminasi ruang operasi akibat kebocoran agen anestesi inhalasi, dan juga meningkatkan risiko aspirasi. Sebaliknya, bila ukuran pipa endotrakeal terlalu besar dapat menyebabkan trauma jalan napas atas (seperti ulserasi, iskemia jaringan, atau pembentukan jaringan parut), meningkatkan risiko terjadi spasme laring, hingga menimbulkan stenosis subglotis. ${ }^{2,3}$

Salah satu metode yang paling umum untuk memperkirakan ukuran pipa endotrakeal pada pasien pediatri adalah menggunakan rumus prediksi berdasar atas usia (Cole, Motoyama, atau Khine formula). Namun berdasar atas penelitian sebelumnya, akurasi dari rumus prediksi berdasar atas usia sangat bervariasi, yaitu sekitar 47-77\%.3.6 Berbagai parameter lain juga dapat digunakan untuk memprediksi ukuran pipa endotrakeal pada pasien pediatri, antara lain prediksi ukuran pipa endotrakeal berdasar atas jari kelingking, berat badan, panjang badan, Broselow tape, ataupun rumus multivariat yang melibatkan tiga parameter sekaligus (usia, berat badan, dan panjang badan)..$^{7-11}$ Namun, parameterparameter tersebut juga memiliki hasil yang bervariasi antara populasi penelitian. Belakangan ini, diameter subglotis mulai sering diteliti sebagai parameter yang dapat dipergunakan untuk memperkirakan ukuran pipa endotrakeal pasien pediatri dengan baik. Evaluasi diameter subglotis dengan akurasi yang tinggi dapat dievaluasi secara radiologis menggunakan MRI, CT-scan, ataupun USG trakea. Diameter subglotis berdasar atas USG lebih sering digunakan karena mudah, dapat dilakukan secara bedsite, dan juga jauh lebih murah daripada menggunakan MRI ataupun CT-scan trakea., ${ }^{3,12-15}$

Penelitian mengenai akurasi prediksi ukuran pipa endotrakeal pada pasien pediatri menggunakan parameter-parameter di atas pada populasi pasien pediatri di Indonesia terutama di RSUD Dr Soetomo Surabaya belum pernah dilakukan. Oleh karena itu, peneliti menganalisis akurasi prediksi pipa endotrakeal tanpa cuff berdasar atas diameter subglotis menggunakan USG dibanding dengan metode prediksi berdasar atas usia dan diameter jari kelingking pada pasien pediatri di RSUD Dr Soetomo yang akan menjalani operasi elektif dengan manajemen jalan napas intubasi.

\section{Subjek dan Metode}

Penelitian ini penelitian prospektif, analitik observasional yang dilaksanakan di RSUD Dr Soetomo Surabaya mulai bulan Februari hingga April 2020 yang telah mendapatkan persetujuan dari Komite Etik Rumah Sakit No.: 2012/119/II/2020. Subjek penelitian ini adalah semua pasien pediatri usia 2 hingga 9 tahun dengan status fisik American Society of Anesthesiologist (ASA) 1 dan 2 yang menjalani anestesi umum dengan manajemen jalan napas intubasi. Metode penelitian ini kemudian dijelaskan kepada orangtua atau wali pasien. Kesediaan mengikuti penelitian ini ditandai dengan menandatangani persetujuan atau informed consent. Pasien pediatri dengan jalan napas sulit memiliki kelainan kongenital yang menyebabkan deformitas ataupun gangguan medis yang menyebabkan kelainan pada laring atau trakea dan akan menjalani operasi jalan napas atau laparoskopi, atau torakotomi dan atau yang berisiko menimbulkan refluks isi lambung dieksklusi dari penelitian ini. 
Teknik pengumpulan sampel menggunakan teknik concsecutive sampling. Semua subjek penelitian mendapatkan perlakuan yang sama dan tidak dilakukan alokasi kelompok. Besar sampel penelitian dihitung menggunakan rumus besar sampel untuk uji korelasi dengan interval kepercayaan 95\% dan a=0,05 maka didapatkan besar sampel penelitian sejumlah 48 pasien.

Pada periode preoperatif variabel usia, jenis kelamin, panjang badan, dan berat badan setiap anak dicatat pada lembar pengumpul data. Panjang badan didapat dengan stadiometer pada posisi berdiri. Berat badan aktual diukur menggunakan timbangan pengukur yang telah dikalibrasi sebelumnya, dengan pasien memakai gaun rumah sakit. Pada periode intraoperatif, pengukuran diameter subglotis dilaksanakan setelah pasien tersedasi dengan pasien diposisikan dalam posisi netral. Identifikasi dilakukan menggunakan USG dengan probe linier. Diameter subglotis ditentukan sebelum pasien diberikan pelumpuh otot dengan terlebih dahulu mengidentifikasi pita suara (gambaran hiperechoic yang ikut bergerak saat pasien bernapas), lalu probe digeser ke arah kaudal untuk memvisualisasikan kartilago krikoid (struktur hipoechoic). Diameter subglotis diperoleh dari diameter transversus kartilago krikoid. Pipa endotrakeal yang digunakan adalah pipa endotrakeal prediksi berdasar atas diameter subglotis menggunakan rumus.

Diameter luar pipa endotrakeal tanpa cuff $=0,55 \mathrm{x}$ (diameter subglotis) $+1,16$, lalu dari hasil perhitungan disesuaikan dengan ukuran pipa endotrakeal yang terdekat. Setelah dilakukan intubasi, pipa endotrakeal tersebut kemudian dilakukan uji ketepatan secara klinis. Pipa endotrakeal aktual yang tepat sesuai klinis didefinisikan sebagai pipa endotrakeal yang menghasilkan audible air leak pada tekanan $10-25 \mathrm{cmH}_{2} \mathrm{O}$. Apabila pipa endotrakeal menghasilkan audible air leak pada tekanan $<10$ atau $>25 \mathrm{cmH}_{2} \mathrm{O}$ maka pipa endotrakeal diganti satu ukuran lebih kecil/ besar sesuai dengan hasil uji ketepatan secara klinis.

Akurasi ukuran pipa endotrakeal prediksi dinilai dengan meregresikan ukuran pipa endotrakeal aktual (tepat sesuai klinis) menggunakan uji korelasi dan agreement test (Uji Kappa). Predictive preformance dinilai menggunakan mean percentage error (MAPE) dan root mean square error (RSME). Mean percentage error (MAPE) diukur dengan membagi ukuran pipa endotrakeal aktual dengan mean error dan dikalikan 100, root mean square error (RMSE) dikalkulasikan

Tabel 1 Demografi Subjek Penelitian

\begin{tabular}{lcc}
\hline \multicolumn{1}{c}{ Data Demografi } & $\mathbf{n = 4 8}$ & Persentase \\
\hline Jenis kelamin & & \\
$\quad$ Laki-laki & 26 & 54 \\
Perempuan & 22 & 46 \\
Status gizi & & \\
$\quad$ Malnutrisi & 2 & 4 \\
Gizi kurang & 12 & 25 \\
Normal & 28 & 59 \\
Gizi lebih & 4 & 8 \\
Obesitas & 2 & 4 \\
\hline
\end{tabular}

Tabel 2 Karakteristik Ukuran Pipa Endotrakeal

\begin{tabular}{|c|c|c|c|c|c|c|c|c|c|}
\hline & \multicolumn{8}{|c|}{ Ukuran Pipa endotrakeal } \\
\hline & & Mean & SD & 4,0 & 4,5 & 5,0 & 5,5 & 6,0 & 6,5 \\
\hline \multicolumn{2}{|c|}{ Pipa endotrakeal aktual } & 5,1354 & ,59911 & $3(6 \%)$ & $\begin{array}{c}11 \\
(23 \%)\end{array}$ & $\begin{array}{c}13 \\
(27 \%)\end{array}$ & $\begin{array}{c}12 \\
(25 \%)\end{array}$ & $9(19 \%)$ & $0(0 \%)$ \\
\hline \multirow{3}{*}{$\begin{array}{l}\text { Pipa } \\
\text { endotrakeal } \\
\text { prediksi } \\
\text { berdasar: }\end{array}$} & USG & 5,1146 & 60353 & $4(8 \%)$ & $\begin{array}{c}10 \\
(21 \%)\end{array}$ & $\begin{array}{c}13 \\
(27 \%)\end{array}$ & $\begin{array}{c}13 \\
(27 \%)\end{array}$ & $8(17 \%)$ & $0(0 \%)$ \\
\hline & Usia & 5,0625 & ,55183 & $0(0 \%)$ & $\begin{array}{c}18 \\
(37 \%)\end{array}$ & $\begin{array}{c}14 \\
(29 \%)\end{array}$ & $8(17 \%)$ & $8(17 \%)$ & $0(0 \%)$ \\
\hline & $\begin{array}{l}\text { Jari } \\
\text { Kelingking }\end{array}$ & 5,2917 & ,73538 & $2(4 \%)$ & $\begin{array}{c}11 \\
(23 \%)\end{array}$ & $\begin{array}{c}13 \\
(27 \%)\end{array}$ & $8(17 \%)$ & 7 (15\%) & $7(15 \%)$ \\
\hline
\end{tabular}


Tabel 3 Uji Korelasi, Agreement Test, dan Predictive Performance dari Pipa Endotrakeal Prediksi terhadap Ukuran Pipa Endotrakeal Aktual

\begin{tabular}{|c|c|c|c|c|c|c|c|c|c|}
\hline \multirow{2}{*}{$\begin{array}{c}\text { Pipa } \\
\text { Endotrakeal } \\
\text { Prediksi } \\
\text { berdasar : } \\
\text { (n=48) }\end{array}$} & \multicolumn{2}{|c|}{ Uji Korelasi } & \multicolumn{5}{|c|}{ Agreement Test (Uji Kappa) } & \multicolumn{2}{|c|}{$\begin{array}{c}\text { Predictive } \\
\text { Performance }\end{array}$} \\
\hline & $\mathbf{r}$ & $\mathbf{p}$ & Tepat & $\begin{array}{c}\text { Under- } \\
\text { estimate }\end{array}$ & Overestimate & $p$ & Kappa & MAPE & RMSE \\
\hline USG & 0,973 & 0,000 & $44(92 \%)$ & $3(6 \%)$ & $1(2 \%)$ & 0,000 & 0,892 & 0,803 & 0,144 \\
\hline Usia & 0,841 & 0,000 & $26(54 \%)$ & $14(29 \%)$ & $8(17 \%)$ & 0,000 & 0,413 & 4,646 & 0,361 \\
\hline Jari kelingking & 0,792 & 0,000 & $20(42 \%)$ & $9(19 \%)$ & $19(40 \%)$ & 0,000 & 0,273 & 6,630 & 0,473 \\
\hline
\end{tabular}

dengan mengakarkan rerata squared error. Analisis statistik dikerjakan dengan statistical product and service solution (SPSS) versi 19.

\section{Hasil}

Penelitian ini melibatkan 48 pasien pediatri usia 2 hingga 9 tahun dengan status fisik (American Society of Anesthesiologist) 1 dan 2 yang menjalani operasi di RSUD Dr Soetomo dengan manajemen jalan napas intubasi. Subjek penelitian terdiri atas 26 pasien lakilaki, 22 pasien perempuan dan status gizi berdasar atas kurva dari CDC dengan indeks massa tubuh normal sebanyak 28 pasien, gizi kurang 12 pasien, malnutrisi 2 pasien $(4 \%)$, gizi lebih 4 pasien $(8 \%)$ dan obesitas 2 pasien (4\%).

Rerata ukuran pipa endotrakeal yang tepat sesuai klinis didapatkan 5,14 $\pm 0,60$ mm dengan rerata ukuran pipa endotrakeal prediksi sebagai perbandingan tergambar pada Tabel 2. Pada penelitian ini didapatkan 4 kali kejadian reintubasi dengan 3 pasien membutuhkan pipa endotrakeal 1 ukuran lebih besar (underestimate) dan 1 pasien diganti ke ukuran yang lebih kecil (overestimate). Pada pasien tersebut, pengamatan saat operasi dan 2 jam setelah operasi (di ruang pulih sadar) tidak didapatkan kejadian laringospasme, bradikardia, nyeri telan, batuk, ataupun suara parau akibat efek samping reintubasi. Uji normalitas sampel menggunakan Uji ShapiroWilk dengan hasil sig 0,001. Pemilihan pipa endotrakeal tanpa cuff yang digunakan pada penelitian ini adalah pipa endotrakeal prediksi berdasar atas diameter subglotis menggunakan USG. Pipa endotrakeal yang tepat sesuai klinis didefinisikan sebagai pipa endotrakeal yang memberikan audible air leak pada tekanan 10-25 $\mathrm{cmH}_{2} \mathrm{O}$. Bila pada tekanan $<10 \mathrm{cmH}_{2} \mathrm{O}$ didapatkan audible air leak maka pipa endotrakeal dinyatakan terlalu kecil dan akan diganti dengan satu ukuran yang lebih besar. Sebaliknya, bila memerlukan tekanan $>25 \mathrm{cmH}_{2} \mathrm{O}$ untuk menghasilkan audible air leak maka pipa endotrakeal dinyatakan terlalu besar dan diganti dengan satu ukuran lebih kecil.

Pada Tabel 3 ditampilkan hasil analisis uji korelasi, asosiasi, dan predictive performance pipa endotrakeal prediksi berdasar atas diameter subglotis, usia, dan diameter jari kelingking terhadap pipa endotrakeal aktual yang tepat sesuai klinis. Dari hasil analisis data didapatkan hasil bahwa pipa endotrakeal prediksi berdasar atas diameter subglotis menggunakan USG memiliki korelasi yang paling baik terhadap pipa endotrakeal aktual dengan $r=0,973$ (nilai $p<0,001$ ) yang dapat memprediksi ukuran pipa endotrakeal dengan tepat pada 44 pasien $(92 \%)$ dengan koefisien kappa 0,892 , nilai $p<0,001$ serta predictive performance dengan mean absolute percentage error terendah $(0,803 \%)$ dan root mean square error yang mendekati nol $(0,144)$.

Prediksi ukuran pipa endotrakeal berdasar atas diameter subglotis mempergunakan USG mampu memprediksi ukuran pipa endotrakeal yang tepat sesuai klinis pada 44 subjek penelitian (92\%), sedangkan pada empat pasien yang memerlukan reintubasi didapatkan kecenderungan akan terjadinya underestimate (tiga pasien, 6\%) 
daripada overestimate (satu pasien, 2\%) dan memerlukan penggantian pipa endotrakeal dengan satu ukuran yang lebih besar ataupun lebih kecil untuk mendapatkan audible air leak $10-25 \mathrm{cmH}_{2} \mathrm{O}$.

Penggunaan parameter usia secara independen memiliki performa yang lebih inferior dibanding dengan diameter subglotis menggunakan USG. Usia mampu memprediksi dengan tepat ukuran pipa endotrakeal aktual pada 26 pasien (54\%), koefisien kappa 0,413 , nilai $\mathrm{p}<0,001$ dengan kesalahan pengukuran pipa endotrakeal berdasar atas usia memiliki kemungkinan kesalahan yang lebih besar bila dibanding dengan pipa endotrakeal yang tepat sesuai klinis dengan MAPE 4,646\% dan RMSE 0,361 .

Dari keseluruhan metode, ternyata metode prediksi ukuran pipa endotrakeal berdasar atas diameter jari kelingking tangan memiliki akurasi yang paling rendah di antara parameter-parameter lainnya dengan kemampuan prediksi dengan tepat hanya pada 20 pasien (42\%), r=0,792; koefisien kappa 0,273 ; nilai $\mathrm{p}<0,001$.

\section{Pembahasan}

Pemilihan ukuran pipa endotrakeal yang tepat pada pasien pediatri merupakan tantangan tersendiri bagi seorang ahli anestesi. Ukuran pipa endotrakeal yang ideal adalah pipa endotrakeal dengan diameter terluar terlebar yang mampu melalui trakea dengan mudah dan lancar (tidak dipaksa) dan memberikan kebocoranyangkecil. ${ }^{6}$ Ukuran pipa endotrakeal terlalu kecil dapat menyebabkan ventilasi tidak adekuat, pengukuran end-tidal $\mathrm{CO}_{2}$ tidak dapat diandalkan, kontaminasi ruang operasi dan peningkatan biaya akibat kebocoran agen anestesi inhalasi, serta juga meningkatkan risiko terjadi aspirasi. Sebaliknya, bila ukuran pipa endotrakeal terlalu besar dapat menyebabkan trauma jalan napas atas (seperti ulserasi, iskemia jaringan, atau pembentukan jaringan parut), meningkatkan risiko spasme laring, hingga menimbulkan stenosis subglotis. Prediksi ukuran pipa endotrakeal berdasar atas beberapa parameter pertumbuhan anak (usia, berat badan, panjang badan, diameter jari kelingking tangan) sangat bervariasi dan dapat sangat berbeda hasilnya antara penelitian menggunakan parameter yang sama pada populasi berbeda. Prediksi ukuran pipa endotrakeal berdasar atas usia merupakan salah satu teknik estimasi yang paling lama dikenal dan paling sering digunakan hingga saat ini. Namun, akurasinya cukup rendah dengan variasi ketepatan sekitar 47-77\% dan bahkan dapat menyebabkan kesalahan prediksi ukuran hingga dua atau tiga ukuran. ${ }^{2,3,5,9}$ Metode prediksi yang ideal adalah metode yang dapat digunakan dengan mudah pada praktik klinis sehari-hari dan memiliki akurasi yang tinggi. ${ }^{6}$

Penelitian akhir-akhir ini mencoba meneliti diameter subglotis sebagai alat bantu prediksi ukuran pipa endotrakeal pada pasien pediatri. Menurut Raphael, $\mathrm{dkk}^{4}$ pengukuran diameter subglotis menggunakan MRI merupakan standar baku emas noninvasif untuk memprediksi ukuran pipa endotrakeal pada pasien pediatri. MRI trakea dapat memberikan data diameter transversus dan antero-posterior dari subglotis sehingga dapat memperoleh diameter jalan napas dengan baik. Namun, MRI atau CT-Scan trakea bukan merupakan pemeriksaan rutin dan bahkan tidak efektif secara pembiayaan bila hanya digunakan untuk mengukur diameter subglotis. ${ }^{4}$ Ultrasonografimerupakanalternatif untuk memprediksi diameter subglotis pada pasien pediatri. Juga dari penelitian sebelumnya didapatkan korelasi yang kuat antara USG dan MRI trakea untuk mengukur diameter transversus dari subglotis., ${ }^{4,13}$ Ketepatan pemeriksaan menggunakan USG kadang bergantung pada operator, namun dikatakan bahwa seorang operator dengan pengalaman 15 kali pemeriksaan sebelumnya mampu mengukur diameter transversus subglotis dengan konsisten dan hasilnya dapat diandalkan. ${ }^{3,12,16}$

Penelitian ini melibatkan 48 pasien di Instalasi Rawat Inap Pediatri RSUD Dr. Soetomo dengan usia 2-9 tahun yang menjalani pembedahan elektif dengan manajemen jalan napas menggunakan pipa endotrakeal 
tanpa cuff. Rentang usia 2-9 tahun dipilih karena pada usia kurang dari dua tahun, dari hasil penelitian Kim dkk. didapatkan korelasi yang buruk pengukuran diameter subglotis pada populasi ini dan pada anak usia 10 tahun atau lebih mulai terjadi proses osifikasi dan kalsifikasi kartilago trakea yang dapat menyebabkan bias pada pemeriksaan sehingga pasien usia kurang dari dua tahun atau lebih dari 10 tahun dieksklusi pada penelitan ini. ${ }^{3,12,14}$ Pipa endotrakeal tanpa cuff dipilih selain karena merupakan rekomendasi pipa endotrakeal pada anak usia kurang dari 10 tahun (kecuali ada indikasi lain) juga diameter luarnya lebih optimal (mendekati ukuran diameter transversus subglotis) bila dibanding pipa endotrakeal memakai cuff. . $^{11,14}$

Pemeriksaan untuk diameter tranversus mempergunakan USG dilakukan pada level subglotis karena merupakan diameter tersempit jalan napas pasien pediatri. ${ }^{3}$ Hasil penelitian pada populasi ini didapatkan bahwa prediksi ukuran pipa endotrakeal berdasar atas diameter subglotis menggunakan USG memiliki korelasi yang paling baik dengan koefisian korelasi 0,973 ( $p<0,001)$, mampu memprediksi dengan tepat pada 91,67\% populasi (koefisien kappa 0,892; nilai $\mathrm{p}<0,001$ ) serta kinerja prediksi yang baik dengan tingkat kesalahan paling rendah (MAPE 0,803\%, RMSE 0,144). Dari penelitianpenelitian sebelumnya didapatkan kesimpulan yang serupa bahwa diameter subglotis berdasar atas USG merupakan parameter yang baik dibanding dengan parameter lainnya untuk memprediksi ukuran pipa endotrakeal pasien pediatri dengan variasi akurasi 60$100 \%{ }^{3,4,11-15}$ Didapatkan satu penelitian yang membandingkan diameter subglotis berdasar atas USG dengan usia untuk memprediksi ukuran pipa endotrakeal pasien pediatri yang mendapatkan hasil berbeda dengan penelitian ini dan penelitian sebelumya dengan akurasi hanya 48\%. Hal ini mungkin disebabkan oleh pipa endotrakeal pada penelitian ini tidak distandardisasi sehingga dapat menimbulkan bias pada penelitian. Juga dengan hasil akurasi yang rendah ini, pada penelitian ini dinyatakan diameter subglotis menggunakan USG masih lebih baik daripada prediksi berdasar atas usia $(40 \%) .^{2}$ Kelebihan metode ini antara lain mudah dilakukan, risiko rendah (non invasif), aman, sensitivitas tinggi, murah, dan juga dapat dilakukan bedside. Seperti metode prediksi lainnya, didapatkan dua kemungkinan terjadi kesalahan, yaitu underestimation dan overestimation. Selain dikarenakan operator dependent, underestimation dapat disebabkan oleh USG hanya mampu mengukur diameter subglotis dan tidak mampu mengukur diameter anteroposterior dari subglotis. Overestimation lebih jarang terjadi karena pengukuran dilakukan pada segmen jalan napas yang relatif sempit, juga disebabkan oleh diameter tranversus relatif lebih kecil dibanding dengan diameter anteroposterior dari subglotis sehingga prediksi berdasar atas diameter subglotis menggunakan USG cenderung undersetimate sesuai dengan hasil penelitian ini. 4,13,14 Pada penelitian ini dilakukan reintubasi pada 4 pasien karena pipa endotrakeal yang dipergunakan tidak tepat secara klinis. Kesalahan pengukuran dapat disebabkan oleh faktor operator ataupun keterbatasan USG untuk menilai diameter anteroposterior subglotis (hanya memprediksi berdasar atas diameter transversus). Pengamatan pada pasien yang mengalami reintubasi di ruang operasi hingga ruang pulih sadar tidak terjadi komplikasi akibat reintubasi seperti spasme, suara parau, ataupun nyeri telan.

Prediksi ukuran pipa endotrakeal pediatri berdasar atas usia merupakan metode yang paling sering digunakan hingga saat ini. Rumus berdasar atas usia menggunakan rumus dari Cole, Kihne atau Motoyama adalah rumus yang paling sering digunakan bergantung pada usia pasien dan jenin pipa endotrakeal yang akan digunakan. Pada penelitian ini didapatkan akurasi prediksi berdasar atas usia menggunakan rumus modifikasi dari Motoyama sebesar 54\% (koefisien kappa 0,413; nilai $\mathrm{p}<0,001)$. Berbeda dengan variabilitas prediksi berdasar atas panjang badan yang diduga dipengaruhi oleh faktor etnis, variabilitas prediksi berdasar atas usia lebih sulit dijelaskan. ${ }^{6}$ Pada hasil beberapa 
penelitian didapatkan akurasi yang cukup tinggi $(60-86 \%)$ pada populasi pediatri di Asia $^{3,7}$ ataupun Amerika, 17,18 namun pada penelitian lain pada populasi ras yang sama didapatkan akurasi yang rendah (2447\%). ${ }^{2,10,13,19}$

Prediksi ukuran pipa endotrakeal berdasar atas diameter jari kelingking tangan didasarkan pada penelitian Allen Hinkle pada tahun 1988 yang menyatakan bahwa jari kelingking tangan memiliki korelasi yang baik dengan ukuran pipa endotrakeal pada pasien pediatri (koefisien korelasi $<0,90$ ). ${ }^{20}$ Namun, pada penelitian tahun 2009 didapatkan akurasi yang rendah (48\%), ${ }^{7}$ serupa dengan hasil penelitian ini dengan akurasi $41,67 \%$ (koefisien kappa 0,273, nilai $\mathrm{p}<0,001$ ). Hal ini mungkin diakibatkan oleh tingginya subjektivitas penilai dalam menentukan ukuran pipa endotrakeal tanpa cuff berdasar diameter jari kelingking tangan. Dari penelitan ini didapatkan hasil bahwa prediksi mempergunakan diameter jari kelingking memiliki akurasi yang paling rendah dibanding dengan modalitas prediksi lainnya.

Kekurangan pada penelitian ini adalah single-center dan pipa endotrakeal tanpa cuff yang distandardisasi mempergunakan pipa endotrakeal dengan merk dagang "BICAKCILAR" sehingga mungkin terjadi bias hasil bila diterapkan pada pipa endotrakeal dengan merk lain terkait sedikit variasi ukuran diameter luar pipa endotrakeal antara merk dagang. Hasil penelitian ini tidak dapat diterapkan pada pipa endotrakeal dengan cuff.

\section{Simpulan}

Diameter subglotis berdasar atas USG memiliki korelasi dan akurasi yang paling baik memprediksi ukuran pipa endotrakeal tanpa cuff pada pasien pediatri.

\section{Daftar Pustaka}

1. Goranović T, Milić M, Djulepa D, Skok I, Jug S, Šakić K, dkk. Haemodynamic changes and intubating conditions during tracheal intubation in children under anaesthesia: a comparative study of two induction regiments. Med Glas. 2009;6(1):104-11.

2. Schramm C, Knop J, Jensen K, Plaschke $\mathrm{K}$. Role of ultrasound compared to agerelated formulas for uncuffed endotracheal intubation in a pediatric populat. Pediatr Anesth. 2012;22(8):781-6.

3. Shibasaki M, Nakajima Y, Ishii S, Shimizu F, Shime N, Sessler DI. Prediction of pediatric end otracheal tube size by ultrasonography. Anesthesiology. 2010;113(4):819-24.

4. Raphael PO, Thasim E, Simon BP, Rajagopal P. Comparative study on prediction of paediatric endotracheal tube size by ultrasonography and by age based formulas. Int J Res Med Sci. 2016;4(7):2528-32.

5. Papagiannopoulou P, Ntritsou V, Pistofidou $\mathrm{K}$, Mademli A, Stefanovits D, Isaakidis A, dkk. The clinical applications of body weight and endotracheal tube size prediction formulas in pediatric patients. Greek E-J Perioperat Med. 2017;16(c):2636.

6. Kumar MG, Atteri M, Batra YK, Yaddanapudi $L$, Yaddanapudi S. Derivation and validation of a formula for paediatric tracheal tube size using bootstrap resampling procedure. Indian J Anaesth. 2019;63(6):444-9.

7. Turkistani A, Abdulla K, Delvi B, AlMazroua K. The 'best fit' endotracheal tube in children. Middle East J Anaesthesiol. 2009;20(3):383-7.

8. Eipe N, Barrowman N, Writer H, Doherty D. A weight-based formula for tracheal tube size in children. Pediatr Anesth. 2009;19(4):343-8.

9. Shih M, Chung C, Su B, Hung C, Wong S, Wong TK. Accuracy of a new body lengthbased formula for predicting tracheal tube size in chinese children. Chang Gung Med J. 2008;31(3):276-80.

10. Hofer CK, Ganter M, Tucci M, Klaghofer R, Zollinger A. How reliable is length-based determination of body weight and tracheal tube size in the paediatric age group? The Broselow tape reconsidered. Br J Anaesth. 2002;88(2):283-5.

11. Singh S, Jindal P, Ramakrishnan P, Raghuvanshi S. Prediction of endotracheal 
tube size in children by predicting subglottic diameter using ultrasonographic measurement versus traditional formulas. Saudi J Anaesth. 2019;13(2):93-9.

12. Altun D, Orhan-Sungur M, Ali A, ÖzkanSeyhan T, Sivrikoz N, Çamcı E. The role of ultrasound in appropriate endotracheal tube size selection in pediatric patients. Paediatr Anaesth. 2017;27(10):1015-20.

13. Bae JY, Byon HJ, Han SS, Kim HS, Kim JT. Usefulness of ultrasound for selecting a correctly sized uncuffed tracheal tube for paediatric patients. J Associat Anaesthet Great Br Ireland. 2011;66:994-8.

14. Mahran E, Adlan S. Routine use of ultrasonography in prediction of uncuffed endotracheal tube size in pediatric patients. Ain-Shams J Anesthesiol. 2019;11(9):1-5.

15. Sutagatti JG, Raja R, Kursi MS. Ultrasonographic estimation of endotracheal tube size in paediatric patients and its comparison with physical indices based formulae: a prospective study. J Clin Diagn Res. 2017;1(5):UC05-8.

16. Gnanaprakasam PV, Selvaraj V. Ultrasound assessment of subglottic region for estimation of appropriate endotracheal tube size in pediatric anesthesia. J Anaesthesiol Clin Pharmacol. 2017;33(2):231-5.

17. Motoyama E. Special Characteristics of pediatric anesthesia. Dalam: Davis P, Cladis F, penyunting. Smith's anesthesia for infants and children. Edisi ke-8. Philadelphia; Elsevier Mosby; 2011. hlm. 1-8.

18. Khine HH, Corddry DH, Kettrick RG, Martin TM, McCloskey JJ, Rose JB, dkk. Comparison of cuffed and uncuffed endotracheal tubes in young children during general anesthesia. Anesthesiology. 1997;86(3):627-31.

19. Cho AR, Kim ES, Lee DW, Hong JM, Kwon JY, Kim HK, dkk. Comparisons of recursive partitioning analysis and conventional methods for selection of uncuffed endotracheal tubes for pediatric patients. Paediatr Anaesth. 2015;25(7):698-704.

20. Hinkle AJ. A rapid and reliable method of selecting endotracheal tube size in children. Anesth Analg. 1988;67(2):92. 